\title{
From Ghosts of the Horseshoe to Ward One
}

Critical Interactives for Inviting Social Engagement with

Instances of Historical Erasure (Columbia, South Carolina) ${ }^{1}$

\author{
Heidi Rae Cooley \\ University of Texas at Dallas \\ Duncan Buell \\ University of South Carolina: Columbia \\ Richard Walker \\ University of South Carolina: Columbia
}

Received: November 2, 2021 / Accepted: November 11, 2021 / Published: November 22, 2021 / Revised: December 5, 2021

\section{Introduction}

A plaque stands at the front gates of the University of South Carolina's historic Horseshoe in Columbia, South Carolina. It has enjoyed that location since being placed there by the Columbia Sesquicentennial Commission of 1938. The plaque reads:

UNIVERSITY OF SOUTH CAROLINA CHARTERED 1801 AS THE S. C. COLLEGE. OPENED JANUARY 10, 1805. ENTIRE STUDENT BODY VOLUNTEERED FOR CONFEDERATE SERVICE 1881. SOLDIERS' HOSPITAL 1862-65. CHARTERED AS U. OF S. C. 1865. RADICAL CONTROL 1873-77. CLOSED 1877-80. COLLEGE OF AGRICULTURE AND MECHANIC ARTS 1880-82. S. C. COLLEGE 1882-87. U. OF S. C. 1887-90. S. C. COLLEGE 1890-1905. U. OF S. C. 1906. FAITHFUL INDEX TO THE AMBITIONS AND FORTUNES OF THE STATE.

Commemorating the "ambitions and fortunes of the state [of South Carolina]," the plaque serves as a reminder of the legacy of the collegiate

1. Article first published by \#IFM2014 Conference: Moura, Hudson et al. (eds.). Interactive Narratives, New Media \& Social Engagement International Conference Proceedings. Reprinted with Author's Permission. 
institution and its connections to a larger history of the nation and Southern values. Reading closely, one might notice the institution's not surprising antebellum political leanings: "Entire student body volunteered for confederate service 1881." Likewise, one might consider the institution's name changes: South Carolina College, University of South Carolina, College of Agriculture and Mechanic Arts, with an eventual return to the University of South Carolina. But what one might gloss over-perhaps because of its ambiguity-is the mention of "Radical control 1873-77" and the immediately following statement, "Closed 1877-80." To what does "radical control" refer? Who or what would have been considered "radical"-under what circumstances? And why the subsequent closure of the university?

Of course, one might conclude that there is a causal relation between the two events: that which was "radical" led to, or even necessitated that the university close for three years. And one might even pause to consider possible reasons for such events. But arriving at any conclusion or simply positing hypotheses requires that one take the time to read the plaque's text, and most visitors to campus do not take the time to do so. Students and faculty-for the most part-have no knowledge of the plaque's contents and meaning; they may not even "see" it. Consequently, they neither formulate hypotheses nor draw conclusions. The challenge for those who would present the entire history of the university becomes this: how to draw attention to the ghosts whose reference lurks in the text of the sesquicentennial plaque? How best to make visible the unacknowledged history of enslaved labour that made possible the 
site now known as the historic Horseshoe? What other instances of historic erasure give foundation to the university landscape?

Ghosts of the Horseshoe and Ward One are critical interactive applications that offer two distinct yet complementary examples for how questions such as the ones just posed might be addressed on-site and in real-time. In what follows, we offer an account of each application and its context. Subsequently, we provide a theoretically informed discussion of how these projects elicit "empathic awareness" and, by extension, inspire a sense of responsibility for a past that remains unacknowledged-one that has ensured the existence and expansion of the physical campus of the University of South Carolina-Columbia.

\section{Historic Erasure I: Slavery and the Historic Horseshoe}

Ghosts of the Horseshoe (Ghosts) is a mobile interactive application that endeavours to bring into view on mobile networked touchscreens (iPad in the first versions) the largely unknown history of slavery that made materially possible the physical site that is the "heart" of the University of South Carolina: the historic Horseshoe. Ghosts deploys game mechanics (i.e., ludic methods), as well as Augmented Reality and GPS functionality, to generate awareness of and to question what otherwise seems ordinary: a grassy space at the center of a university campus. Ghosts organizes content into three distinct but overlapping themes: (1) architectural ghosts (e.g., razed outbuildings); (2) human ghosts (e.g., un/named enslaved persons); and (3) the historic wall that delimits the Horseshoe grounds. Content pertaining to these three threads is called-up according to four time periods: 1801-1820 (early institution); 1821-1840 
(institutional growth and the building of the wall); 1841-1860 (late antebellum institution); and 1861-1880 (the institution during the Civil War and through the Reconstruction period).

Ghosts' root screen interface is an 1884 Sanborn Fire Insurance map of the South Carolina College campus. A compass rose appears atop this map and indicates in real-time the geolocative position of the participant (or "interactant" hereafter). As the interactant traverses the Horseshoe grounds, previously faint fingerprint icons populating the map interface grow increasingly more visible, indicating that the interactant is near a content point. Content points open onto audio, textual, and visual information pertinent to a particular building or, in the case of the historic wall, an architecturally significant feature. In some instances, interactants listen to, for example, the voice of "Henry" (a real figure, whose history is partly known) as he details his existence as a slave at South Carolina College-his purchase, his escape, his capture, and his subsequent sale. In other instances, interactants confront digitized historical documents indicating the cost of "hiring" an enslaved person, whose identity might be indicated by a name (e.g., "Anna") or by category (e.g., "washerwoman," "boy"). And in other instances, a historic photograph of an outbuilding (i.e., slave quarters) appears in the landscape where it would have existed (had it not been torn down) overtop the device's real-time camera view. (Of course, it is worth noting that the sibling outbuilding still standsunidentified-at the left flank of what is now the President's House.) 
Should an interactant venture beyond the Horseshoe campus proper, she will encounter opportunities to learn about historic preservation. The wall (ca. 1835-1836) that encloses the historic Horseshoe is suffering from general deterioration and weathering, disrepair, and defacement. University Archivist Elizabeth West and University Architect Derek Gruner together have secured funds to preserve the historic wall-which was originally built to confine students to the campus grounds. Ghosts features a Citizen Archeology function that allows interactants to document instances of deterioration, damage, etc., in order to support the preservation efforts of West and Gruner. As an interactant moves along the Horseshoe perimeter, she is invited to focus more concertedly on minute details of the wall's structural status: crumbling mortar, splintering bricks, poor repointing, invasive foliage, eye-screws, etc. In keeping with the Ghosts logic, fingerprint icons direct interactants to points of concern. Now such icons, when activated, inform the interactant of kinds of deterioration. Moreover, she is invited to take photos of instances of deterioration, etc., and contribute those images to a backend database that will parse all incoming images for easy assessment by West and Gruner.

Ghosts of the Horseshoe endeavours to encourage a shift in attitude with respect to the historic Horseshoe, its relation to the University of South Carolina, and the institutional and socio-cultural politics that are responsible for what exists as a surprisingly intact "landscape of slavery." We acknowledge that its approach is subtle; we avoid direct accusations. That is, Ghosts is not interested in leveraging claims against the past or the current institution that 
enjoys what the past has made possible. Instead, it uses juxtaposition to underscore convenient omissions or revisionist interpretations of a history that remains unfamiliar, unacknowledged. For example, as one nears the sesquicentennial plaque (discussed above), Ghosts signals that new content is available via the Augmented Reality functionality. When one raises the touchscreen device and focuses the camera on the physical plaque, an overlay appears onscreen and supplants the plaque in real-time. Now the interactant reads:

UNIVERSITY OF SOUTH CAROLINA CHARTERED 1801 AS THE S. C. COLLEGE. ENSLAVED LABOR RESPONSIBLE FOR CONSTRUCTION ON AND MAINTENANCE OF CAMPUS 1801-1965. OPENED JANUARY 10, 1805. FIRST MAJORITY AFRICAN-AMERICAN PUBLIC COLLEGE 1873-77. CLOSED 1877-80. COLLEGE OF AGRICULTURE AND MECHANIC ARTS 1880-82. S. C. COLLEGE 1882-87. U. OF S. C. 1887-90. S. C. COLLEGE 1890-1905. U. OF S. C. 1906. FAITHFUL INDEX TO THE AMBITIONS AND FORTUNES OF THE STATE.

Now modified, the text states: "Enslaved labour," "First majority AfricanAmerican public college," and "Closed." The enumeration of historical occurrences works suggestively. The site being commemorated is the result of enslaved labour; it became the first majority African-American public college in the US during Reconstruction; it was closed and reopened as a completely different institution and remained resegregated until 1963. There is no mention of the institution's confederate affiliations or that it reopened in 1880 as an allwhite agricultural college. While these exclusions might very well be interpreted as instances of counter-erasure, they serve to emphasize the ways in which race and racial politics are fundamental-indeed, foundational to USC's identity as a public institution. 


\section{Historic Erasure 2: Urban Renewal and Ward One}

The University of South Carolina did not reintegrate until 1963. The university's website describes this moment of political significance in the following way: "On Sept. 11, 1963, Henrie D. Monteith, Robert Anderson and James Solomon became the first African-American students to enroll at the university in the 20th century; in 1965, Monteith became the first AfricanAmerican graduate, earning a B.S. in biochemistry" (http://www.sc.edu/). A single compound sentence celebrates the fact of integration and the successful completion of a degree by an African American student: a tidy but perfunctory account that glosses over an eighty-six-year history of prohibited access based on race. And perhaps not drawing attention to this history of exclusion seems somehow reasonable. But the very same years of segregation saw African Americans employed by the university. They maintained the facilities and grounds; they worked as custodial staff, emptying trash and sweeping floors; they prepared and served meals to students and faculty. And a majority of these employees lived in neighbourhoods around the campus. Collectively, these neighbourhoods comprised a voting district known as Ward One.

Ward One emerged in the late nineteenth century. Situated between the boundaries of present-day Pickens, Huger, Heyward, and Gervais streets, about one square mile in area, Ward One grew into a bustling, predominantly African American business and residential area. By the early twentieth century, Ward One residents had developed their own culture and built their own institutions. 
Having faced the daunting challenges of racial segregation, two world wars, and the Great Depression, the downtown community boasted churches, schools, businesses, and civic organizations. African American residents owned property and held prominent positions in the community. But established Ward One families began to relocate to more upscale areas of town and the state-even the country; they sold their homes. Incoming inhabitants could not afford to own, so they rented. New property owners-in most cases, well-established white citizens-proved disinclined to maintain their rentals. And in the late 1950s, The Columbia Housing Authority, under the direction of housing commissioner Joseph E. Winter, officially designated Ward One to be a "blighted" area. Ward One is not the only community to suffer the consequences of policies that resulted in the eviction and displacement of African American families. Across the United States mid-century (ca. late 1940s 1970s), cities pursued projects of urban renewal and revitalization. These initiatives functioned to identify areas of impoverishment for subsequent demolition and rebuilding. In Columbia, SC, this meant a drastic overhaul of the area around USC: alleys and streets disappeared; homes were bulldozed; churches-like Union Baptist and Jones Memorial-relocated across town; and schools and businesses closed down. In the wake of demolition, USC expanded its campus, purchasing the newly available land-a practice that has analogs nationwide, including, for example, Indiana University-Purdue University, Indianapolis; University of Chicago; University of Michigan-East Lansing; Stanford; and University of North Carolina-Chapel Hill. Where once homes, a baseball field, businesses, schools, and churches stood, one now sees USC's Koger Center, Strom Thurmond 
Fitness and Wellness Center, and Greek Village. And while plaques mark where, for example, the Celia Dial Saxon School used to stand, few passersby pause long enough to read about the historical relevance of the sites so marked.

In response to such glaring omissions of history, we are developing a mobile application and a complementary interactive website that invite participants to consider both the local and national policies and politics that fueled urban renewal in Columbia, SC and elsewhere in the country. Called Ward One, the project focuses on how matters of race have functioned to reconfigure the institutional landscape of USC (from its inception as South Carolina College in 1801). Moreover, the project suggests how other similar landscapes in the US likewise "benefited" from federally sanctioned redevelopment-or revitalization-efforts that displaced black communities. By raising questions about how local, state, and federal efforts succeeded in eradicating "blighted" areas, the project makes visible an oft-ignored history that is national in scope.

Using the affordances of both touchscreen and desktop interfaces, Ward One mobilizes local news footage, photographs, and other archival materials that serve as evidence of the historic place and its demolition, as well as the site's initial appropriation by the City of Columbia and the Columbia Housing Authority and its subsequent acquisition and transformation by the University of South Carolina. It features Ward One community representatives, who offer narratives of forced relocation and efforts to protest such acts of "progress." These reflections and memories of those who refuse to forget offer a counter- 
narrative of cultural renewal. In this way, Ward One endeavours to harness the spirit of the Ward One community, which lives on in the stories shared by and ongoing efforts of people who remember a time when they called Ward One home. At the same time, it places these local stories in the larger context of midtwentieth-century "reconstruction" that was enabled by discourses of "poverty" and "slum life" and the "bourgeois imagination" (Mullins and Jones, 2011, 34) that rationalized such discourses and the legal instrument of eminent domain by which private property was appropriated.

The Ward One mobile application, in its first instantiation, features the historic Palmetto Compress building, an early 20th century (ca. 1917) cotton warehouse that recently escaped plans for demolition that will be renovated and will house a museum that the Ward One Organization will curate. The corners of Blossom and Huger, where the warehouse sits, serve as the point of departure for the app, which will follow an initial set of individual itineraries (e.g., as determined by Ms. Mattie Anderson-Roberson and Deacon Arthur F. Jones, former residents who are active in the Ward One community organization). Incorporating audio-visual media, the app will follow these former Ward One inhabitants as they traverse the former Ward One terrain. Interactants will see where once stood Ms. Mattie Anderson-Roberson's childhood home stood; she will follow Deacon Jones through alleys where he played chess. The interactive website frames these local stories in the context of national urban renewal and tenement reform initiatives. 
Toward Empathic Awareness, Critical Interaction, and Social Engagement

The state of South Carolina boasts a population of 4,625,364, approximately $28 \%$ of which is African American (2010). By contrast, the state's flagship research university has a student body of only $11 \%$ African American/Black (http://www.forbes.com/colleges/university-of-southcarolina-columbia/). Neither Ghosts nor Ward One will change these statistics in any direct or immediate way. But in tandem, that is, as a suite of interactive applications, they might very well inspire in others an "empathic awareness" of how race matters to a "sense" of responsibility for a past whose politics still bears on the present.

We cannot change the past. And, with tensions still high, because race is still the divisive primary issue, at least in the South if not the entire United States, reconciliation and understanding are unlikely to result from "preaching." We argue that the most productive means to secure social engagement can be by means that are subtle and evocative. Ghosts and Ward One attempt to show that "bodies are not merely texts or performances but flesh and bone, histories and entanglements, suffering and illness, capabilities and desires, life and deathin short, bodies are material and not just materialized" (Casper and Moore, 2009, 16).

The records that survive of the enslaved persons who made the bricks and built the buildings and Wall of the USC Horseshoe are predominantly records of labour, contracted for and treated entirely as a commodity. We have attempted with Ghosts to engage the interactant with the reality that these 
enslaved persons were persons, to make her aware that the buildings and Wall are perhaps all that remains of their lives and work, and that we should be reminded of the (almost) intentional erasure in the record of their presence on campus.

Moving from Ghosts to Ward One, we find ourselves not with a paucity of information about the individuals who will populate the interactive narrative but with a surplus. Our task here is to re-create in the new medium the stories and the sense of community that is still felt by the former residents. The task is made harder by the need to select a small number of narratives to be presented from the very large number that could be presented. On the other hand, the task is made easier by the fact that former residents are involved in the development of Ward One. Their stories can be told in the first person. Their sense of community can be felt in the give and take of their discussions with each other. The official historical record is one of urban renewal to eliminate blight, with the university as the benefactor expanding (for the most part, only recently) into the land area made available by the displacement of that community. The community itself is still present, more than forty years later. Ward One endeavours to elicit an empathic awareness in its interactants in order to cultivate reconciliation along and across the colour line and, by extension, across campus community divides. It endeavours to make all of us aware of the human cost of decisions-federal and local-whose result seems only to be modern buildings. 
Finally, we acknowledge the role played here by the new medium, by the mobile platform that permits both Ghosts and Ward One to present the history to the interactants. These are interactive presentations of history, with all the emotive power of imagery, audio, and the sense of being present on the location where the history took place. In this regard, we endeavour, as Monica J. Casper and Lisa Jean Moore assert, to "reveal, resituate, and recuperate" those people whose stories, indeed whose bodies, in the instance of the historic Horseshoe, have fallen victim to historical erasure (Casper and Moore, 2009, 15). It is worth reminding ourselves that race and reconciliation are-150 years after the end of the Civil War, 60 years after Brown v. Board of Education, and 50 years after the Civil Rights Bill-still enormously troubling issues for the United States. It is time to acknowledge that "The act ... of focusing on [those whose voices have been muted] in a critical way ... is an ethical responsibility" (Casper and Moore, 2009, 15). 


\section{Bibliography}

Buell, D. A., and H. R. Cooley. "Critical Interactives: Improving public understanding of public policy," Bulletin of Science, Technology, and Society, 32 (2012): 486-493.

Casper, Monica J., and Lisa Jean Moore. Missing Bodies: The Politics of Visibility. New York and London: NYU Press, 2009.

Cooley, H. R., and D. A. Buell. "Ghosts of the Horseshoe, a Mobile Application: Fostering a New Habit of Thinking about the History of University of South Carolina's Historic Horseshoe." Annual Review of Cultural Heritage Informatics, 1 (2014): 193-212.

Mullins, R. and L. C. Jones. (2011). "Archaeologies of Race and Urban Poverty: The Politics of Slumming, Engagement, and the Color Line," Historical Archaeology 45,1 (2011): 33-50.

Weyeneth, R., et al. "Slavery at South Carolina College," 1801-1865: The Foundations of the University of South Carolina, 2012.

http://library.sc.edu/digital/slaveryscc/ [September 15, 2014] 